\title{
The Current Situation of Gynecologic Laparoendoscopic Single-Site Surgery in a Chinese Teaching Hospital
}

\author{
Xiang Tang*, Xianghui Su, Xiaolong Jin, Yali Zhu, Qiong Xu, Chunfang Cai and Zhuohui Zhong \\ Department of Minimal Invasive Gynecology, Guangzhou Women and Children's Hospital, Guangzhou Medical University, China
}

*Corresponding author: Xiang Tang, Department of Minimal Invasive Gynecology, Guangzhou Women and Children's Hospital, Guangzhou Medical University, Guangzhou, China.

To Cite This Article: Xiang Tang, The Current Situation of Gynecologic Laparoendoscopic Single-Site Surgery in a Chinese Teaching Hospital. 2020 - 7(3). AJBSR.MS.ID.001154. DOI: 10.34297/AJBSR.2020.07.001154.

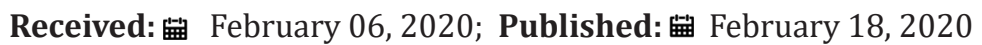

Keywords: Laparoendoscopic Single Site Surgery; Transumbilical Single-Port Surgery; Conventional Laparoscopic Instruments; Gynecologic Surgery.

\section{Introduction}

As one type of the laparoscopic surgery, the laparoendoscopic single-site (LESS) surgery has been developed in an attempt to further reduce the morbidity and scarring associated with surgical intervention [1,2]. Single-site Gynecologic Surgery is widely carried out all over the world during the recent years. More and more gynecological endoscopic surgeries use this single-site technology, especially transumbilical single-port. In china, the number of LESS has increased dramatically from 2017. Our hospital started to carry on this technology from September 2017. Many researches have indicated advantages of it, such as less postoperative pain and quick recovery, less skin scar etc. Some results are conflicting [3-10]. The advantages of LESS are still uncertain.

\section{Current Situation in our Hospital}

From November 2017 to November 2018,105 LESS gynecological surgeries were performed, 35 ovarian cystectomies, 38 unilateral fallopian tube resections, 22 myomectomies and 10 hysterectomies through LESS. Only one surgery needed one more additional port. No patients have severe complications. Operative time, intraoperative blood loss and perioperative complications have no difference, compared with the conventional laparoscopy. The LESS laparoscopy group had less postoperative pain scores and longer bowel recovering time, compared with the conventional laparoscopy (Table 1).

\begin{tabular}{|c|c|c|c|c|}
\hline Table 1: Clinical Characteristics and Operative Data of LESS. \\
\hline Variable & Ovarian Cystectomy & Myomectomy & Salpingectomy & Hysterectomy \\
\hline N & 35 & 38 & 32 & 10 \\
\hline Patient age & $32.67 \pm 6.32$ & $38.82 \pm 6.52$ & $20.85 \pm 2.50$ & $44 \pm 3.13$ \\
\hline BMI & $21.73 \pm 3.35$ & $22.20 \pm 3.42$ & $61.26 \pm 30.68$ & $126.26 \pm 36.48$ \\
\hline Operating time & $107.67 \pm 29.85$ & $116.36 \pm 59.12$ & $20.70 \pm 56.27$ & $40.90 \pm 46.47$ \\
\hline Blood loss & $26.24 \pm 18.78$ & $69.09 \pm 81.56$ & $1.26 \pm 0.71$ & $2.16 \pm 0.71$ \\
\hline Pain score 24h & $1.09 \pm 0.64$ & $1.36 \pm 1.03$ & $1.25 \pm 0.50$ & $1.95 \pm 0.80$ \\
\hline Bowel recovering time & $1.65 \pm 0.54$ & $1.71 \pm 0.51$ & $3.22 \pm 2.43$ & $4.27 \pm 2.63$ \\
\hline hospital stay days & $3.64 \pm 1.26$ & $3.81 \pm 1.69$ & & \\
\hline
\end{tabular}




\section{Discussion}

Laparoendoscopic single site surgery(LESS)is a single port technique through the umbilicus, in the past 10 years, LESS has emerged as a potentially less invasive alternative to multiport laparoscopy.

At the beginning, a homemade single port is easier to get, low cost and has a good socioeconomic performance. YH Park was the first person who reported that he uses a homemade single port device to perform laparoendoscopic single-site nephrectomy [11]. Many countryside hospitals in china used this kind of homemade single port.

In the application of any new technique, the safety of the patients is always the most important. After a median follow-up period of 3 months, there is no complaint of the LESS surgery. All the LESS group patients were fully satisfied with the appearance of the incisions. We think all surgeons could complete LESS after the learning curve.

In this study, all the patients are benign. Most of patients care about the appearance of the incisions, especially the young patients. Now in our department, many patients are willing to take LESS. Some Chinese doctor applied LESS to malignant diseases, such as cervical cancer, early Ovarian Cancer and endometrial carcinoma [12-14].

We think that the future thread would be single-site robotic surgery associated AI technology.

\section{Conclusion}

LESS surgery is less invasive, suitable and safe for gynecological surgery. It has been widely promoted in China.

\section{References}

1. Fan X, Xu K, Lin T, Liu H, Yin Z, et al. (2013) Comparison of transperitoneal and retroperitoneal laparoscopic nephrectomy for renal cell carcinoma: a systematic review and meta-analysis. BJU Int 111(4): 611-621.

2. Autorino R, Desai MM, Gettman M, Gill IS, Kavoussi LR, et al. (2011) Laparoendoscopic singlesite and natural orifice transluminal endoscopic surgery in urology: a critical analysis of the literature. Eur Urol 59(1): 26-45.
3. Bansal D, Riachy E, Defoor WR Jr, Reddy PP, Minevich EA, et al. (2014) Pediatric varicocelectomy: a comparative study of conventional laparoscopic and laparoendoscopic single-site approaches. J Endourol 28(5): 513-516.

4. Friedersdorff F, Aghdassi SJ, Werthemann P, Cash H, Goranova I, et al. (2013) Laparoendoscopic single site (LESS) varicocelectomy with reusable components: comparison with the conventional laparoscopic technique. Surg Endosc 27(10): 3646-3652.

5. Lee SW, Lee JY, Kim KH, Ha US, (2012) Laparoendoscopic single-site surgery versus conventional laparoscopic varicocele ligation in men with palpable varicocele: a randomized, clinical study. Surg Endosc 26(4): 1056-1062.

6. Marte A, Pintozzi L, Cavaiuolo S, Parmeggiani P (2014) Single-incision laparoscopic surgery and conventional laparoscopic treatment of varicocele in adolescents: Comparison between two techniques. Afr J Paediatr Surg 11(3): 201-205.

7. Wang J, Xue B, Shan YX, Cui Y, Tao W, et al. (2014) Laparoendoscopic single-site surgery with a single channel versus conventional laparoscopic varicocele ligation: a prospective randomized study. J Endourol 28(2):159-164.

8. Youssef T, Abdalla E (2015) Single incision transumbilical laparoscopic varicocelectomy versus the conventional laparoscopic technique: A randomized clinical study. Int J Surg 18: 178-183.

9. Gasparri ML, Mueller MD1, Taghavi K1, Papadia A1 (2018) Conventional versus Single Port Laparoscopy for the Surgical Treatment of Ectopic Pregnancy: A Meta-Analysis. Gynecol Obstet Invest 83(4): 329-337.

10. Demirayak G, Özdemir İA1, Comba C1, Aslan Çetin B2, Aydogan Mathyk B3, et al. (2020) Comparison of laparoendoscopic single-site (LESS) surgery and conventional multiport laparoscopic (CMPL) surgery for hysterectomy: long-term outcomes of abdominal incisional scar. J Obstet Gynaecol 40(2):1-5.

11. Yong Hyun Park, M.Y.K, Min Su Jeong, Hwang Choi, Hyeon Hoe Kim (2009) Laparoendoscopic Single-Site Nephrectomy Using a Homemade Single-Port Device for Single-System Ectopic Ureter in a Child: Initial Case Report. Journal of Endourology, 23(5): 833-835.

12. Chen S, Zheng Y, Tong L, Zhao X, Chen L, et al (2020). Laparoendoscopic Single-site Radical Hysterectomy with Vaginal Closure and Without Uterine Manipulator for FIGO IB1 Cervical Cancer. J Minim Invasive Gynecol. S1553-4650(20)30036-4.

13. Lin C, Ying Z, Xiao Rong Q, Sijing C, Ling M, et al. (2019) LESS with Suture Suspension for Early-Stage Adnexa Cancer Staging. JSLS 23(3): e.00024.

14. Chen S, Qi X, Chen L, Yi Q1, Dong S, et al. (2019) Laparoendoscopic Single-site Surgery for Comprehensive Staging of Early Ovarian Cancer. J Minim Invasive Gynecol 26(5): 806. 